\title{
YOUTH INJURIES AS A FUNCTION OF SEX, LIFE HISTORY, AND NEIGHBORHOOD SAFETY
}

\author{
Laura Johnsen $^{1}$, Daniel J. Kruger ${ }^{2}$, Glenn Geher ${ }^{3}$, Rebecca Shaiber ${ }^{4}$, Justin Garcia ${ }^{5}$ \\ and Aron Wiegand ${ }^{3}$ \\ 1Department of Anthropology, Binghamton University, New York, USA \\ ${ }^{2}$ School of Public Health, University of Michigan, Ann Arbor, Michigan, USA \\ 3Department of Psychology, State University of New York at New Paltz, New York, USA. \\ ${ }^{4}$ Department of Psychology, Loyola University Chicago, Chicago, Illinois, USA \\ ${ }^{5}$ Kinsey Institute, Indiana University Bloomington, Bloomington, Indiana, USA
}

\section{geherg@newpaltz.edu}

\begin{abstract}
From infancy until early adulthood, men have higher mortality rates due to external causes than do women. Human evolutionary behavioral scientists have framed this sex difference in pre-adulthood mortality risk as an outcome of sex-specific intrasexual competition, resulting in a higher propensity for physical risk taking in males. The current research builds upon this work, by retrospectively exploring patterns of injury occurring in childhood and adolescence. We predicted sex-specific effects with respect to the ways individuals adjust to their environments behaviorally, including: life history strategy, childhood and adolescent injury, and age at sexual debut. Seven hundred eighty five (173 men, 612 women) U.S. university students completed an anonymous questionnaire including metrics considering sociodemographics, significant childhood and adolescent injuries (including injury severity and quantity of stitches received), perceived neighborhood safety, age of incidence for first sexual intercourse, number of sexual partners, and life history strategy. Individuals with faster life history strategies were more likely to have sustained serious injuries in their youth (requiring stitches, surgery, or medication). Also, those with a Fast LHS are more likely to be male, define their neighborhoods as dangerous, and have their first sexual encounter at an earlier age. Adaptive behavioral responses triggered by latent factors in local ecology may promote riskier behaviors in modern environments, helping to explain the etiology of risk-taking behaviors and injury among youth today. We discuss results in terms of predictive human evolutionary theory.
\end{abstract}

Keywords: Childhood, adolescence, injury, life history strategy, accidents. 


\section{INTRODUCTION}

A central tenet of sexual selection theory is that conspecifics of the same sex will compete with each other over reproductive access to individuals of the opposite sex (Darwin, 1871; Dugatkin, 2013; Gray \& Garcia, 2013; Geher \& Kauffman, 2013). In humans and other animals, this is most commonly, although not exclusively (Fisher, 2013; Rosvall, 2011), described in terms of male intrasexual competition and subsequent female mate-choice following competition outcomes. Among males, such competition can often involve high-risk behavior and risk exposure in order to obtain and demonstrate resources, status, and overall fitness (Symons 1979; Townsend, 1999). To be expected, these patterns are often most notable when individuals are reaching reproductive maturity and begin seeking mates, and often coincide with a suite of behavioral patterns associated with maturation into adulthood. In many closely related primate (and some ancestral) species, migrating from natal groups to find mates and occupy new social units minimizes inbreeding and increases genetic diversity. Risktaking behavior may have emerged to promote more effective migration amongst those whose overall fitness is contingent on their readiness to survive, interact socially, and compete for mates in a novel environment (Spear, 2000). While a clear link between male risk culture and avoidable death may make it seem maladaptive in the modern environment, there are many foreseeable reasons why risk-taking may be a historically beneficial mechanism for survival and future fecundity in those transferring from pre to post-adolescence.

Behavioral dispositions, regardless of the number of stories which could purport their potential benefit, require a possible heritable component in order to be investigated through an evolutionary lens. Toward this end, multiple studies have been conducted suggesting heritability of risk-taking behavior, ranging from exploratory behavior in rodents and birds, to economic risk-taking and substance abuse in human beings (Van Oers et. al, 2004; Zhong et. al, 2009; Sapienza et. al., 2009; Zuckerman M. \& Kuhlman D.M., 2000, Apicella et. al., 2008). In boys, longitudinal studies indicate a 55\% heritability rate of risktaking behavior emerging around the age of 14 (Anokhin, Golosheykin, Grant, \& Heath, 2009). This is backed by research indicating genetically maintained, heritable biomarkers as factors regulating risk-taking and novelty seeking in humans (Ebstein et. al, 1996; Ebstein, R.P, 1997; Zuckerman, 1994). Findings like these, while not necessarily providing a specific mechanism, lend credence to the heritability of behavioral phenotypes associated with risk-taking.

Recent research on health outcomes from an evolutionary perspective suggests that the nature of human mortality is highly sex-differentiated and, as Kruger and Nesse (2006) have argued, follow from expectations rooted in sex-specific costs of intrasexual competition. Although a higher vulnerability to disease is a major contributor to the death of young men (Kruger \& Nesse, 2006), young men are more likely than are young women to die of external causes of death such as accidents and homicides (Wilson \& Daly, 1985; Waller, Baker, \& Szocka, 2012). Moreover, young men have greater incidence rates of traumatic injuries that require emergency care (Fingerhut \& Gillum, 1995). Men tend to die at a faster rate than women all across the lifespan; this male-to-female mortality ratio (M:F MR) is a universal pattern with cultural variations in magnitude (Kruger \& Nesse, 2004). 
Research suggests that men and women vary considerably in frequency and severity of risk behaviors (Geary, 2010; Wilson \& Daly, 1985; Spear, 2010), with competition and risk behavior having major impacts on survival and reproduction. A meta-analysis of some 150 studies concluded a clear pattern of sex differences in risk-taking behavior, with males engaging in more risk across a variety of domains, with the effect decreasing with age (possibly in concert with age-related declines in hormonal mechanisms governing such sex differences) (Byrnes, Miller, \& Schafer, 1999). This disparity is further compounded by men's reduced sensitivity to competitive and risk-induced stress as compared with women in similar scenarios (Kerr \& Vlaminkx, 1997; Lenroot \& Giedd, 2010). Additionally, associations have been found between free testosterone levels in men at the onset of puberty, and social affiliation with male peers oriented towards greater risk-taking behavior (Vermeersch et. al., 2008). This creates an environment with self-perpetuating social elements that exaggerate male risk-taking.

Extensive endocrinological evidence in a number of mammalian species links youth and pubertal activity of male gonadal hormones (Phoenix et. al., 1959; Schulz, Figueira \& Sisk, 2009) to the augmentation of neural structures subserving engagement in (Sisk \& Zehr, 2005; Schulz \& Sisk, 2006), emotional tolerance of (Aikey et. al., 2002; Lürzel, et. al., 2011), and perception of reward stemming from risky behavior (Braams et. al., 2015; Irwin, 1993). Androgen-fueled restructuring responsible for the emergence of "male-typical" behavior in juveniles of many species (Schulz, Salas-Ramirez \& Sisk, 2009, Campbell et. al., 2009), is a likely candidate for explaining discrepancies in risk that emerge between juvenile males and females, become more marked in adolescence, and persist throughout the lifecourse.

Evidence points to physiological reorganization starting in this juvenile period and extending through adolescence, as precipitating the development of characteristic risk behavior in later life. Cross-culturally and historically, youth face a variety of challenges to survival. As highlighted by data drawn from hunter-gather and historical mortality data, mortality rates are estimated at approximately $27 \%$ for infants during the first year of life, and $47.5 \%$ for children prior to reaching puberty (Volk \& Atkinson, 2013). Unintentional injury is consistently the leading cause for fatalities in children and adolescents (Centers for Disease Control and Prevention, 2014; Borse, Rudd, Dellinger, \& Sleet, 2013; Deal, Gomby, Zippiroli, \& Behrman, 2000). Boys, middle-to-late adolescents, minorities, and low-income youth are the most vulnerable populations to unintentional injury (Grossman, 2000). Additionally, aggression and externalizing behavior are substantial social risk factors for unintentional injuries in children and adolescents (Wazana, 1997; Jokela, Power, \& Kivimäki, 2009). "Risky play" (including "Rough-and-tumble play" and play-fighting), is a form of aggressive play developing early in juveniles that creates potential for physical injury (Sandseter \& Kennair, 2011), but ostensibly serves as a way for youth to mimic competitive behaviors seen in adulthood. Growing increasingly sexually dimorphic with age, this semi-risky behavior observed among juveniles has been shown to be governed by similar biological factors as adult risk-taking (Geary, 1999; Cooke \& Woolley, 2009).

As these juveniles develop, the gonadal hormones prompting the emergence of risktaking may also be differentially activated by environmental novelty (Wingfield, 2013), making youth environment a critical limiting factor to consider when viewing behavioral trends throughout the lifecourse. Support for expanding focus to include periods prior to 
adolescence when considering risk-behavior increases when we consider how environment may interact with sensitive periods in the early organizational phase of organization-activation type systems (Schulz, Molenda-Figueira \& Sisk, 2009); for example, research observing that exposure to unpredictable environments from ages 0-5 is more highly associated with risky sexual behavior, aggression, and criminal delinquency at age 23, than exposure at ages 6-16 (Simpson et. al., 2005). From an evolutionary perspective, modern urban environments are characterized by group sizes and living conditions that yield unprecedented exposure to novelty and competitive stress. In comparative research, environmental effects related to urbanization, are indicated in rapidly shifting tolerance for novelty exploration and competitive risk (Atwell et. al., 2012).

Evaluating individual risk-taking in terms of its actual link with differential approaches to reproductive behavior can be done through examining its commonalities with Life History Strategy. Life History Theory provides a theoretical framework to consider evolutionary processes throughout the lifecourse, as individuals respond dynamically to their environment to maximize survival and reproduction (Stearns, 1992). Resulting patterns of reproduction and behavior may cluster in what are framed as adaptive life history strategies (Møller \& Garamszegi, 2012). The concept of life history strategy operates simultaneously in the realms of evolution and development, and examines traits like the timing of puberty, ages at sexual debut and first birth, and level of parental investment. Whether a "slow" or "fast" life history strategy proves more adaptive is putatively regulated by factors like environmental harshness (external factors regulating morbidity-mortality) and the level of predictability of this harshness in terms of spatial localization and timing (Ellis et. al. 2009). Slow life history strategies may be an adaptive response for individuals whose current fitness is not inherently under threat, whereas those who face unpredictable or increased physical/resource competition may benefit from a faster life history strategy (characterized by earlier age of first reproduction, increased annual fecundity, reduced parental investment, greater risk taking, increased habitat exploration, higher aggression, etc.; see Wolf et. al, 2007) (Belsky, 2012; Sheppard, Garcia, \& Sear, 2015).

\section{Current Study}

The current work seeks to expand on what we know about the effects of environmental factors on risky behavior in humans, exploring the effects of perceived neighborhood safety, biological sex, and life history strategy on markers of physical injury during development. To this point, although sex differences in mortality have been examined closely from an evolutionary perspective, sex differences in youth injuries have not [see Konner (2010) for a thoroughly detailed examination of childhood with an evolutionary biocultural perspective]. This research also examines factors associated with childhood and adolescent injuries, such as whether the injuries were controllable, as well as possible links between early life injuries and later sexual behavior. We examine a total of three hypotheses in the current study. The first two hypotheses (below) regard relationships between childhood and adolescent injury, life history strategy, and sexual behavior, and our third examines these factors in relation to neighborhood safety scores. 
The first hypothesis ( $\mathrm{H} 1)$ is that overall life history and measures of sexual activity (age at first sexual encounter and total number of sexual partners) can be predicted by risk-taking measures of youth injury (both numeracy and severity). An individual with a slower life history strategy (as measured using a survey score; Figueredo et al., 2006) is predicted to demonstrate reduced engagement in risky behavior compared to individuals with fast-paced life history strategies (Wang, Kruger, \& Wilke, 2009). In addition, age at first sexual experience and number of sexual partners should be predicted by youth injury-related variables. Participants with a faster-paced life history strategy are predicted, roughly speaking, to be more likely to invest effort in mating as opposed to parenting (Figueredo et. al, 2006). In the current study, stitches were used as an empirically quantifiable marker of injury severity. As such, participants with comparatively high numbers of sexual partners, and those who had a younger age at first sexual experience, are predicted to have had a greater number of stitches. Under premodern conditions, men who displayed risky non-sexual behavior are hypothesized to have competed by gambling bigger losses for bigger gains, and thus received access to more or higher quality mating partners (Gray \& Garcia, 2013; Low, 1998; Wilson \& Daly, 1993). This hypothesis serves to connect quantifiable markers of injury (a reliable indicator of risk-taking behavior) to sexual behavior as these factors relate to overall reproductive fitness.

The second hypothesis $(\mathrm{H} 2)$ is that injuries resulting from risky, but controllable, events will correspond to faster individual life history strategy. Individuals with a slow life history strategy will likely be less prone to controllable accidents when compared to people with a faster life history strategy. This hypothesis is also based on the premise that a fast life history strategy corresponds to risky behavior (Wang, Kruger, \& Wilke, 2009). In this case, accident controllability refers to whether the participant was in control of the circumstances that ultimately caused his or her accident(s) during childhood and adolescence.

Our third hypothesis (H3) is that poor childhood and adolescent neighborhood safety will correspond to riskier sexual behavior and more severe injury during young adulthood. The central premise of life history theory is that individuals have evolved to respond to their local ecologies. Poor neighborhood quality (to the point of qualifying as an unsafe environment), is thus predicted to correspond to adoption of a faster life history strategy (Nettle, 2010). Poor childhood and adolescent neighborhood safety should correspond to more severe injuries. This relationship is expected to be partially mediated by life history strategy as a mechanism to explain risk in context. As individuals respond to their local ecology by way of life history strategy, another potential outcome is regulation of sexual behavior (Belsky, 2012; Cameron, 2011; Nettle, Coall, \& Dickins, 2011). Similarly, poor neighborhood safety should correspond to risky sexual behaviors. Again, this relationship is expected to be partially mediated by individual life history strategy. 


\section{METHOD}

\section{Participants}

Participants were mainly recruited from the Psychology Department human subject pools at two state universities, one a smaller sized campus located in the U.S. Northeast and the other a large-sized campus in the U.S. Midwest. Participants were also recruited through email and advertisements on the social networking website Facebook ${ }^{\oplus}$. In total, the current study includes 785 participants: 173 men $(M$ age $=22.38$ years; $S D=6.95)$ and 612 women $(M$ age $=21.41$ years; $S D=5.36)$. Some students received Psychology Department subject pool credit for their participation.

\section{Procedure}

The questionnaire was administered via the online survey tool SurveyMonkey ${ }^{\circledast}$ and took approximately 30 minutes to complete. Questions included basic sociodemographics, neighborhood safety, number of sexual partners, age at first sex, significant childhood and adolescent injuries, and the mini-k scale (Figueredo et al., 2006). Participants could report and describe up to 10 injuries, however we analyzed only the first injury as it was rare for participants to report more than one injury. Basic sociodemographics included sex, birth order, ethnicity or race, year in college, relationship status, and description of the neighborhood, as well as family income during childhood and adolescence. All aspects of the current study were approved by a university Institutional Review Board.

\section{Measures mini-k scale}

The mini-k is a 20-item measure derived from the Arizona Life History Battery, intended to measure an individual's life history strategy (Figueredo et al., 2006). mini-k is a shortened version of the K-scale, with fewer questions and shown to be similarly valid as, and convergent with, the larger K-scale measure (see Figueredo, Vásquez, Brumbach, Sefcek, Kirsner, \& Jacobs, 2005); mini-k has also been demonstrated to be valid crossculturally (Figueredo et al., 2006). The mini-k scale has received extensive validation (Figueredo et al., 2014; Figueredo \& Wolf, 2009; Gladden, Figueredo, \& Jacobs, 2008; Gladden, Sisco, \& Figueredo, 2008), ( $\alpha=.74)$. mini-k assesses individual differences in endorsement of items related to (slow-paced) life history strategy. Participant agreement/disagreement responses are used to indicate tendency toward life history strategy (fast-paced to slow-paced). Items include questions about sociosexuality (e.g., "I would rather have one than several sexual relationships at a time"), and questions about investment in kin (e.g., "I have a close and warm relationship with my own children"). If participants did not have children, they could skip the child-related questions. Scores on this measure tend to be normally distributed, and the psychometric nature of the scale allows it to be used to examine behavioral variability on life history strategy dimension both within sex as well as across sexes (Figueredo et al., 2006).

\section{Childhood/adolescent injuries}

Participants were asked to select what type of injuries, if any, they experienced during childhood. Participants mainly reported injuries they received during childhood and adolescence because no age range was provided. Participants were given three options to 
best describe specific injuries: "broken bone," "laceration," or "concussion." Laceration was defined for participants as "implies a torn or jagged wound." Concussion was defined for participants as "a brain injury that may result in a bad headache, altered levels of alertness, or unconsciousness." Participants were also asked their age when the injury occurred. Participants would then, in free-response text boxes, explain how the injury transpired. Injury descriptions were later coded by the researchers to determine if the participant was directly or indirectly capable of controlling the events precipitating their injury. In most descriptions, participants usually explicitly said who was "at fault" for the accident, and researchers determined whether unilateral modification of behavior on behalf of the participant could notably affect the injury outcome. If controllability was undeterminable, it was coded as "other." Participants were then asked to rate severity of the injury on a 1-5 bipolar scale ranging from "least severe" (1) to "very severe" (5). Last, participants were asked to report on any medical interventions involved with the injury: if they went to a doctor or hospital, if they received stitches and if so how many, if the injury required surgery, and if the injury resulted in any permanent damage. All relevant questionnaire items are included as they appeared to participants in appendix A.

\section{Neighborhood safety}

While describing the environment you grew up in, participants were asked "How safe was it to walk around alone in your neighborhood during the daytime" and "How safe was it to walk around alone in your neighborhood after dark." Response options were on a 4point scale: 1 = extremely dangerous, 2 = somewhat dangerous, 3 = fairly safe, $4=$ completely safe. Responses for perceived daytime and nighttime neighborhood safety were summed (maximum possible score of 8) to create a composite perceived neighborhood safety score.

\section{Sexual behaviour}

Participants were asked "How many sexual partners have you had" and "How old were you when you first had sex" with free-response text boxes. Responses were cleaned to all be in numeric form, and any ambiguous responses were removed. 


\section{RESULTS}

Scores for neighborhood safety, the mini-k, and ratings of injury severity exhibited acceptable levels of skewness and kurtosis, between -2 and +2 . Scores for neighborhood safety and the mini-k had a small degree of negative skew; ratings of injury severity appeared approximately normal. These patterns extended to multivariate normality. Variables appeared to exhibit linear relationships and did not exhibit multicollinearity. Regression residuals indicated homoscedasticity. Confidence limits for autocorrelation functions were between -0.2 and +0.2 , indicating no autocorrelation.

\section{Hypothesis 1 (H1): Life History Strategy Predicts Health-Related Outcomes}

Life history strategy (LHS) scores (higher scores on mini-k indicating slower LHS) and measures of sexual tendencies (age at first encounter and total number) can be predicted by risk-taking measures of youth injury (both numeracy and severity). Correlations between life history strategy, sexual behavior, neighborhood safety, and markers of injury are presented in Table 1 . Women in the sample scored significantly higher $(M=$ 25.26, $S D=14.09)$ than $\operatorname{men}(M=18.86, S D=16.86), t(582)=4.32, p<.05, d=.41$. Life history strategy correlated with age at first sexual experience, $r(418)=.223, p<.01$; faster LHS corresponded to a younger age. Life history strategy correlated with receiving stitches, $r(522)=-.094, p<.05$ (faster life history strategy went with a higher likelihood of receiving stitches). Life history strategy also was correlated with receiving surgery for the injury, $r(521)=-.123, p<.01$ (faster LHS corresponded to a higher likelihood of surgery). Similarly, number of stitches was positively correlated with number of sexual partners, $r(536)=.23, p<.01$, and negatively correlated with age at first sexual experience $r(109)=.20, p<.05$.

LHS also correlated with the total number of life sexual partners (faster LHS corresponded to more partners): $r(501)=-.131, p<.01$. Age at first sexual experience and number of sexual partners were also predicted by youth injury-related variables (See Table 1 for full list of zero-order correlations). 
Table 1: Correlations Between Life History Strategy, Sexual Behavior, Neighborhood Safety and Markers of Injury.

$\begin{array}{llllllllllll}1 & 2 & 3 & 4 & 5 & 6 & 7 & 8 & 9 & 10 & 11\end{array}$

1. $\operatorname{Sex}^{1}$

2. $\operatorname{mini-k^{2}} \begin{array}{r}.18^{* *} \\ 584\end{array}$

$\begin{array}{cccc}\text { 3. NH } & -.05 & .17^{* *} & \\ \text { Safety }^{3} & 680 & 502 & \\ & & & \\ \text { 4. Stitches }^{4} & -.19 & -.09^{*} & -.98 \\ & 626 & 522 & 537\end{array}$

5. \# of $\quad-.08 \quad-.16 \quad .01 \quad .1$

$\begin{array}{lllll}\text { Stitches } & 626 & 128 & 124 & 144\end{array}$

$\begin{array}{llllll}\text { 6. \# of sex } & -.05 & -.13^{* *} & .02 & .15^{* *} & .23^{* *}\end{array}$

partners $\quad \begin{array}{lllll}676 & 501 & 668 & 536 & 536\end{array}$

7. Age at $\quad-.06 \quad-.22^{* *} \quad .14^{* *} \quad-.06 \quad-.20^{*} \quad-.23^{* *}$

$\begin{array}{lllllll}\text { first sex } & 548 & 418 & 543 & 436 & 109 & 544\end{array}$

$\begin{array}{llllllll}\text { 8. Visit } & -.09 & -.08 & -.01 & .39^{* *} & -.06^{* *} & .07 & -.00\end{array}$

$\begin{array}{llllllll}\text { hospital } & 548 & 523 & 539 & 619 & 445 & 538 & 437\end{array}$

9. Receive $\quad-.07 \quad-.12^{* *} \quad \begin{array}{lllllll} & -.04 & .25^{* *} & .18^{*} & .09 & -.07 & .18^{* *}\end{array}$

$\begin{array}{lllllllll}\text { surgery } & 625 & 521 & 536 & 615 & 144 & 534 & 433 & 618\end{array}$

$\begin{array}{lllllllllll}10 . & .01 & -.90^{*} & -.02 & .13^{* *} & .11 & -.09^{*} & -.075 & .093^{*} & .19^{* *}\end{array}$

$\begin{array}{llllllllll}\text { damage } & 628 & 524 & 540 & 618 & 145 & 538 & 439 & 621 & 620\end{array}$

\begin{tabular}{cccccccccccc} 
11.Visit & -.07 & .05 & .00 & $.16^{* *}$ & .04 & -.02 & .04 & $.47^{* *}$ & $.13^{* *}$ & $.10^{*}$ & \\
doctor $^{4}$ & 625 & 521 & 536 & 617 & 140 & 534 & 534 & 619 & 614 & 618 & \\
12. & -.05 & $-.10^{*}$ & $-.10^{*}$ & $.22^{* *}$ & $.18^{*}$ & $.12^{* *}$ & -.06 & $.30^{* *}$ & $.36^{* *}$ & $.27^{* *}$ & $.28^{*}$ \\
12. & 628 & 523 & 539 & 613 & 144 & 538 & 538 & 615 & 612 & 615 & 612 \\
\hline
\end{tabular}

${ }^{*} p<.5,{ }^{* *} p<.01$

Key:

1Sex was labeled as $1=$ man, $2=$ woman. (e.g., mini-k was positively correlated with sex which means that females had higher mini-k scores)

${ }^{2}$ For the injury variables of stitches, visiting hospital, receiving surgery, permanent damage, visiting doctor, no $=1$, yes $=2$. A negative correlation with those variables means that the participants who said no to receiving a certain variable had lower scores (e.g. slower paced life history strategies (high mini-k scores) were less likely to report that the injury resulted in permanent damage) 


\section{Hypothesis 2 (H2): Accident Controllability Relates to Life History Strategy and Biological Sex}

Accident controllability (whether the accident was perceived as within the participant's control) was related to sex and life history strategy (see Figure 1). Participants who reported being in control of the accident had significantly higher $\mathrm{K}$ scores (and thus slower Life History Strategies) than others $F(1,502)=11.48, p<.01$. Per Figure 1, there was a trend toward an interaction between accident controllability and sex such that men who were not in control of the accident had particularly low K scores, but this interaction was not significant.

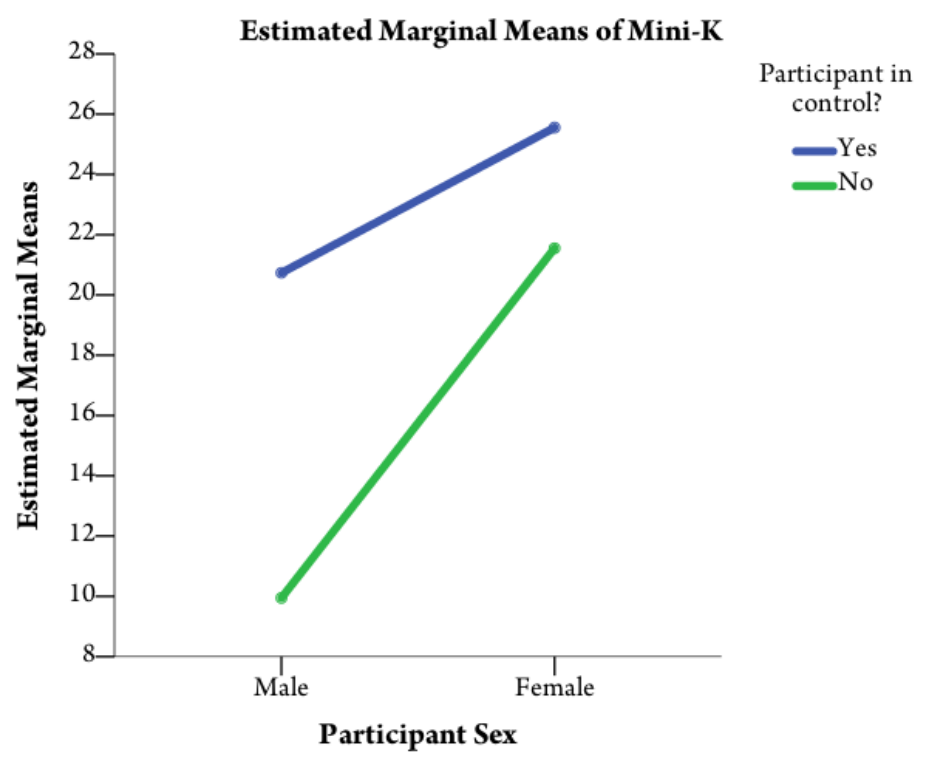

Figure 1: K-Score as it Relates to Sex and Controllability

\section{Hypothesis 3 (H3): Neighborhood Safety Relates to Life History Strategy and Health-Related Outcomes}

The prediction that poor perceived neighborhood safety during youth would correspond to more severe youth injuries, as partially mediated by life history strategy, was supported by the data (neighborhood safety correlations can be seen in Table 1). Slower life history strategy corresponded to relative neighborhood safety, $r(502)=.166, p<.01$. Neighborhood safety negatively correlated with the severity of the injury $r(539)=-.103$, $p<.05$. Poorer neighborhood safety scores were connected to higher reports of injury severity (See Table 2). 
Table 2: Multiple Regression Predicting Number of Stitches.

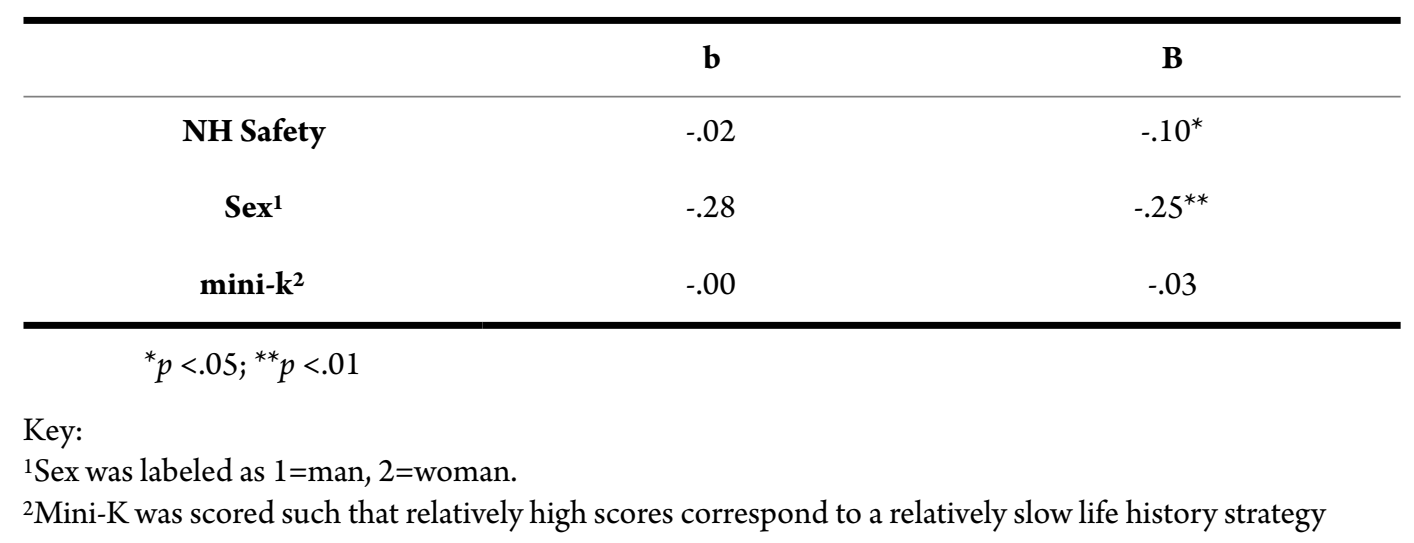

Table 3: Multiple Regression Predicting Injury Severity.

\begin{tabular}{ccc}
\hline & $\mathbf{b}$ & $\boldsymbol{\beta}$ \\
\hline NH Safety & -.07 & $-.13^{*}$ \\
Sex $^{1}$ & -.15 & -.06 \\
mini-k $^{2}$ & -.00 & $-.13^{*}$ \\
\hline${ }^{*} p<.01$ & &
\end{tabular}

Key:

${ }^{1}$ Sex was labeled as $1=$ man, $2=$ woman.

${ }^{2} \mathrm{Mini}-\mathrm{K}$ was scored such that relatively high scores correspond to a relatively slow life history strategy

To see if neighborhood safety also directly predicted receiving stitches and injury severity, we conducted a multiple regression. The variability in receiving stitches was found to be significantly predicted by the set of predictor variables including neighborhood safety $R^{2}=.01, F(1,445)=4.85, p<.05$ (see Table 2). Variability in injury severity was also significantly predicted by the set of predictor variables, including life history strategy $R^{2}=.13, F(1,446)=8.13, p<.05$ (See Table 3 ). As suspected, poor neighborhood safety in childhood and adolescence also predicted risky sexual behaviors. Perceived neighborhood safety scores positively correlated with age at first sexual experience, $r(534)=.14, p<.01$. Lower ratings of neighborhood safety during youth corresponded to lower ages of first sexual experience. A path model (see Figure 2) also shows how life history strategy partially mediates correlations between neighborhood safety and other variables. Family income, neighborhood safety, and participant sex were entered as exogenous variables, life history scores were allowed to mediate the relationship between exogenous variables and the predicted outcomes of the number of sexual partners, age at first sexual intercourse, and the objective and subjective severities 
of first injury. Non-significant paths were trimmed from the model to yield the parsimonious solution.

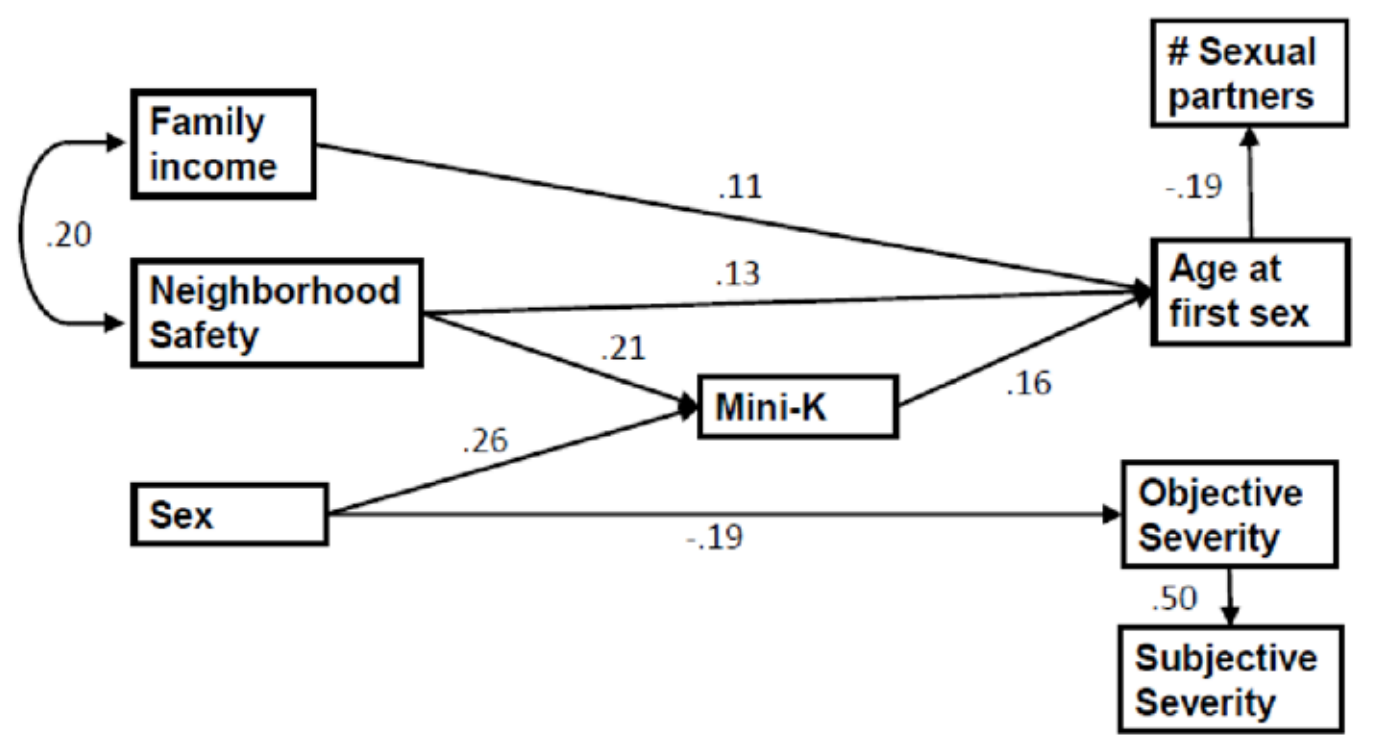

$\chi_{(19)}^{2}=27.74, p=.088, \chi^{2} /$ d.f. $=1.46, \mathrm{GFI}=.980, \mathrm{NFI}=.878, \mathrm{CFI}=.956, \mathrm{RMSEA}=.037$

Figure 2: Unique Predictors in Theoretical Model

\section{DISCUSSION}

Recent research on the male-female mortality ratio from an evolutionary perspective has shown that men - relative to women - are more likely to die at all phases of life, and this trend is particularly pronounced during the years associated with courtship and the development of mateships (Kruger \& Nesse, 2006). The current research explores this same phenomenon in terms of non-lethal injury, using retrospective accounts of individuals' youth. Instead of examining mortality, this research examines the nature of significant youth injuries, or those that occurred prior to 18-years of age. Applying a life history approach, we predicted that individuals with faster life history strategies would be more likely to have had a significant youth injury, would be more likely to have had adverse consequences associated with such an injury, would be more likely to manifest early onset of sexual behavior, would be more likely to come from challenged and unsafe neighborhoods, and would be more likely to be men.

Our results indicate that sex, life history, and neighborhood safety are all related to youth injuries in varying degrees. Our hypotheses about the interaction between life 
history strategy and injury-related variables were supported. Those with faster life history strategies were more likely to receive stitches, surgery, and medication for the injury, have the injury result in permanent damage, and rated the injury for higher severity. The number of stitches moderately correlated with life history strategy scores. Moreover, participants with lower life history strategy scores (Fast LHS) were also more likely to report a lack of control over their accidents. This last point about the accident controllability and life history strategy is counter to what was predicted. The data indicate that people with fast life history strategies were more likely to have injuries that occurred in situations out of their control (e.g., getting pushed by a peer).

We would predict that those with a faster-paced life history strategy would have a higher number of injuries compared to their slower-paced peers due to their engagement in risky behavior. Although our data do not support a direct link between a faster-paced life history strategy and increased occurrence of injuries throughout a participant's youth, (as we did not ask about accrued number of injuries during adolescence), future research may examine if a faster-paced life history strategy would correspond to total number of injuries across one's lifetime with respect to one's social networks.

However, our findings did show that fast-paced life history strategy corresponded to greater severity of injury outcomes. A faster-paced life history strategy (lower K scores) also corresponded to receiving stitches, receiving surgery, having the injury result in permanent damage, and overall injury severity. These findings suggest that those with faster-paced life history strategies are more likely, when compared to those in our sample with slower-paced life history strategies, to have injuries that could potentially be lifethreatening. By situating youth injury as a potential consequence of adaptive developmental trajectories, these findings help us better understand risk factors associated with youth injury and perhaps also help better explain global mortality patterns (Kruger \& Nesse, 2006). Overall, men had faster life history strategies than did women in our sample (as measured by the mini-k, which conceptualizes life history strategy in terms of an approach to life that either focuses on somatic versus mating effort).

Participants with fast-paced life history strategies also had lower ages of first sexual experience. This finding suggests that those more focused on mating effort, as opposed to survival/family-oriented effort, engage in sexual activity at a younger age. This regulation of sexual behavior is presumably an adaptive response to maximize an individual's potential reproductive success (Belsky, 2012); quicker initiation of sexual activity could result in earlier onset and faster intervals for individuals to produce and rear potential offspring.

Neighborhood safety scores were positively correlated with socioeconomic status (see Figure 2). Those who reported higher socioeconomic status while growing up also reported higher youth neighborhood safety scores. Neighborhood safety was directly linked to slower-paced life history strategy scores; those with lower neighborhood safety scores had a faster-paced life history strategy. This finding is consistent with research showing that a fast-paced life history strategy is an adaptive response to environmental unpredictability (Belsky, Schlomer, \& Ellis, 2011). This is also consistent with Nettle's (2010) findings that children in deprived neighborhoods experience faster paced life history trajectories, with less investment in growth and development, and subsequent negative impacts on health. 
Lower ages of first sexual experiences also corresponded to low neighborhood safety scores. Taken together with correlations between low neighborhood safety and fastpaced life history strategy, this might imply that neighborhoods with low safety, which are also unpredictable environments, may be an underlying contributor that fuels a faster-paced life history strategy. This in turn may encourage a lower age of first sexual experience. Such a trend is consistent with research demonstrating that individuals adjust their survival and reproductive efforts to their local environments, adaptively responding by way of life-history strategy (Nettle, 2010; O'Brien, \& Wilson, 2011).

In an intriguing twist, those with slower-paced life history strategies reported having more control over incidents resulting in injury. The theory was that if Fast LHS were positively related to risk taking behavior, those individuals would be more likely to engage in risky scenarios voluntarily. However if we consider the literature, we can see where the semantics of this question comes into play. Fast LHS is inherently linked to exposure to an environment that is perceived as unpredictable and uncontrollable, therefore it makes logical sense that individuals with Slow LHS would be more likely to report that they had a modicum of "control" over risky choices, regardless of whether they opted to engage in them voluntarily. It is also possible that individual possession of an internal v. external locus of control can influence whether past events are attributed to uncontrollable, external factors, or personal responsibility.

\section{Limitations and future directions}

Although our study produced several interesting findings, there were several limitations, which we hope to address in future research. First, "sex" was not explicitly defined for participants as a particular type of sexual experience (e.g., penetrative vaginal intercourse). As previous work has shown (Sanders, Hill, Yarber, Graham, Crosby, \& Milhausen, 2010), this presents a limitation to our understanding of what types of sexual behaviors participants may have been reporting on. Another limitation was that we did not explicitly define "childhood" for our participants. Most participants described injuries that occurred before the age of 21 years, which means our data include injuries that occurred during childhood as well as adolescence. Future research will need to more carefully define these terms for participants; to both connect to the existing developmental literature, and to lessen confusion for participants.

Issues with participants' self-reported memory of injuries that occurred over the past 10-20 years, perhaps explaining why it was rare for more than one injury to be reported. A longitudinal study that chronicles participants' injuries from childhood into adulthood could provide more detailed and accurate accounts of reported injury. More information regarding injury demographics, such as the total number of severe injuries incurred throughout participants' lifetimes, and how often they are injured compared to their peers, would be helpful in better understanding variation in injuries and factors predicting injury occurrence. If an individual has more injuries compared to their peers, this difference could be used as an indicator for participation in risky activities. This would help further our understanding of how youth environment is related to adult behavior and peer groups, and how those demographics are related to injury and life history strategy. 
Not all human beings are equivalently equipped to deal with certain types of risk. General factors like general propensity toward violence and general physique, differ between the sexes; as do physical consequences associated with outcomes like pregnancy. Therefore, it would be inappropriate to assess men and women as taking the exact same amount of risk, though they are engaging in the same action. Future studies should consider these inconsistencies when measuring risk taking between groups. In addition, by looking more closely at the relationship between age and injuries sustained, we could obtain a better perspective on risk-taking behaviors that may be defined as naïve. Lack of familiarity with one's environment may result in unknowingly partaking in a risky behavior, potentially resulting in severe injury, that may have been avoided had they known the potential consequences associated with their actions.

In any future continuation of this line of study, it would be beneficial to source from populations extending beyond university students. Greater diversity in SES of participants, including a wider range of youth neighborhoods, would allow for a higher range of mini-k and neighborhood safety scores to compare. This is likely to increase the effect sizes observed linking youth injuries, neighborhood safety, and life history strategy.

\section{REFERENCES}

Aikey, J. L., Nyby, J. G., Anmuth, D. M., \& James, P. J. (2002). Testosterone rapidly reduces anxiety in male house mice (Mus musculus). Hormones and Behavior, 42(4), 448-460. DOI

Anokhin, A. P., Golosheykin, S., Grant, J., \& Heath, A. C. (2009). Heritability of risktaking in adolescence: A longitudinal twin study. Twin Research And Human Genetics, 12(4), 366-371. DOI

Apicella, C.L., Dreber, A., Campbell, B., Gray, P.B., Hoffman, M., \& Little, A.C. (2008). Testosterone and financial risk preferences. Evolution and Human Behavior, 29(6), 384-390. DOI

Atwell, J. W., Cardoso, G. C., Whittaker, D. J., Campbell-Nelson, S., Robertson, K.W., \& Ketterson, E. D. (2012). Boldness behavior and stress physiology in a novel urban environment suggest rapid correlated evolutionary adaptation. Behavioral Ecology, 23(5), 960-969. DOI

Belsky, J. (2012). The development of human reproductive strategies: Progress and prospects. Current Directions in Psychological Science, 21(5), 310-316. DOI

Belsky, J., Schlomer, G. L., \& Ellis, B. J. (2011). Beyond cumulative risk: Distinguishing harshness and unpredictability as determinants of parenting and early life history strategy. Developmental Psychology, 48(3), 662-673. DOI

Borse, N.N., Rudd, R.A., Dellinger, A.M., \& Sleet, D.A. (2013). Years of potential life lost from unintentional child and adolescent injuries - United States, 2000 - 2009. Journal of Safety Research, 45, 127-131. DOI 
Braams, B. R., van Duijvenvoorde, A. C., Peper, J. S., \& Crone, E. A. (2015). Longitudinal changes in adolescent risk-taking: a comprehensive study of neural responses to rewards, pubertal development, and risk-taking behavior. The Journal of Neuroscience, 35(18), 7226-7238. DOI

Byrnes, James P., David C. Miller, and William D. Schafer (1999). Gender differences in risk taking: A meta-analysis. Psychological Bulletin, 125(3), 367-383. DOI

Cameron, N.M. (2011). Maternal programming of reproductive function and behavior in the female rat. Frontiers in Evolutionary Neuroscience, 3:10. DOI

Campbell, B.C., Dreber, A., Apicella, C.L., Eisenberg, D.T.A., Gray, P.B., Little, A.C., Garcia, J.R., Zamore, R.S., \& Lum, J.K. (2010). Testosterone exposure, dopaminergic reward, and sensation-seeking in young men. Physiology and Behavior, 99(4), 451-456. DOI

Cooke, B. M., \& Woolley, C. S. (2009). Effects of prepubertal gonadectomy on a maletypical behavior and excitatory synaptic transmission in the amygdala. Developmental neurobiology, 69(2-3), 141-152. DOI

Centers for Disease Control and Prevention. (2014). Web-based Injury Statistics Query and Reporting System. Retrieved September 10, 2016 from https://www.cdc.gov/ injury/wisqars/.

Darwin, C. (1871). The Descent of Man, and Selection in Relation to Sex (1st ed.). London: John Murray. Reprinted DOI

Deal, L.W., Gomby, D.S., Zippiroli, L., \& Behrman, R.E. (2000). Unintentional injuries in childhood: Analysis and Recommendations. The Future of Children, 10(1), 4-22. $\underline{\mathrm{DOI}}$

Dugatkin, L.A. (2013). Principles of Animal Behavior (Third Edition). W.W. Norton \& Company.

Ebstein, R.P., Novick, O., Umansky, R., Priel, B., Osher, Y., Blaine, D., \& Belmaker, R. H. (1996). Dopamine D4 receptor (D4DR) exon III polymorphism associated with the human personality trait of novelty seeking. Nature genetics, 12(1), 78-80. DOI

Ebstein, R.P. \& Belmaker, R.H. (1997). Saga of an adventure gene: novelty seeking, substance abuse and the dopamine D4 receptor (D4DR) exon III repeat polymorphism. Molecular Psychiatry, 2(5). $\underline{\mathrm{DOI}}$

Ellis, B. J., Figueredo, A. J., Brumbach, B. H., \& Schlomer, G. L. (2009). Fundamental dimensions of environmental risk. Human Nature, 20(2), 204-268. DOI

Figueredo, A.J., Vásquez, G., Brumbach, B.H., Schneider, S.M.R., Sefcek, J.A., Tal, I.R., Hill, D., Wenner, C.J., \& Jacobs, W.J. (2006). Consilience and life history theory: From genes to brain to reproductive strategy. Developmental Review, 26(2), 243-275. DOI

Figueredo, A.J., Vásquez, G., Brumbach, B.H., Sefcek, J.A., Kirsner, B.R., \& Jacobs, W. (2005). The K-Factor: Individual differences in life history strategy. Personality and Individual Differences, 39(8), 1349-1360. DOI 
Figueredo, A.J., \& Wolf, P.S.A. (2009). Assortative pairing and life history strategy: A cross-cultural study. Human Nature, 20(3), 317-330. DOI

Figueredo, A. J., Wolf, P. S. A., Olderbak, S. G., Gladden, P. R., Fernandes, H. B. F., Wenner, C., Hill, D., Andrzejczak, D. J., Sisco, M. M., Jacobs, W. J., Hohman, Z. J., Sefcek, J. A., Kruger, D., Howrigan, D. P., MacDOnald, K., \& Rushton, J. P. (2014). The psychometric assessment of human life history strategy: A meta-analytic construct validation. Evolutionary Behavioral Sciences, 8(3), 148 - 185.

Fingerhut, L.A., \& Gillum, B.S. (1995). Injury among persons 1-24 years of age in the United States: Data from the National Center for Health Statistics. In Proceedings of the International Collaborative Effort on Injury Statistics. Hyattsville, MD: Public Health Services.

Fisher, M. L. (2013). Women's intrasexual competition for mates. In: M. L. Fisher, J. R. Garcia, R. Sokol Chang (Eds.), Evolution's empress: Darwinian perspectives on the nature of women, 19-42. DOI

Furr-Holden, C. D. M., Milam, A. J., Reynolds, E. K., MacPherson, L., \& Lejuez, C. W. (2012). Disordered neighborhood environments and risk-taking propensity in late childhood through adolescence. Journal of Adolescent Health, 50(1), 100-102. DOI

Geary, D. C. (1999). Evolution and developmental sex differences. Current Directions in Psychological Science, 8(4), 115-120.

Geary, D. C. (2010). Male, Female: The Evolution of Human Sex Differences, $2^{\text {nd }}$ Ed. Washington, D.C.: American Psychological Association. DOI

Geher, G., Kaufman, S.B. (2013). Mating intelligence unleashed: The role of the mind in sex, dating, and love. Oxford University Press.

Gladden, P.R., Figueredo, A.J., \& Jacobs, W.J. (2009). Life history strategy, psychopathic attitudes, personality, and general intelligence. Personality and Individual Differences, 46(3), 270-275. DOI

Gladden, P.R., Sisco, M., \& Figueredo, A.J. (2008). Sexual coercion and life history strategy. Evolution and Human Behavior, 29(5), 319-326. DOI

Gray, P.B., \& Garcia, J.R. (2013). Evolution and Human Sexual Behavior. Cambridge, MA: Harvard University Press.

Grossman, D.C. (2000). The history of injury control and the epidemiology of child and adolescent injuries. The Future of Children, 10(1), 23-52. DOI

Irwin, C.R. (1993). Adolescence and risk taking: How are they related. In N.J. Bell, R.W. Bell (Eds.), Adolescent risk taking (pp. 7-28). Thousand Oaks, CA US: Sage Publications, Inc.

Jokela, M., Power, C., \& Kivimäki, M. (2009). Childhood problem behaviors and injury risk over the life course. Journal of Child Psychology and Psychiatry, 50(12), 1541-1549. DOI

Kerr, J.H., \& Vlaminkx, J. (1997). Gender differences in the experience of risk. Personality and Individual Differences, 22(2), 293-295. DOI 
Konner, M. (2010). The Evolution of Childhood: Relationships, Emotion, Mind. Cambridge, MA: Harvard University Press.

Kruger, D.J., \& Nesse, R. M. (2004). Sexual selection and the Male:Female Mortality Ratio. Evolutionary Psychology, 2(1), 66-77. DOI

Kruger, D. J., \& Nesse R. M. (2006). An evolutionary life-history framework for understanding sex differences in human mortality rates. Human Nature, 17(1), 74-97. DOI

Low, B. (1998). The Evolution of Human Life Histories. In: Handbook of Evolutionary Psychology: Issues, Ideas, and Applications, Charles Crawford and Dennis Krebs (Eds.), pp. 131-161. Mahwah, New Jersey: Lawrence Erlbaum Associates.

Lenroot, R. K., \& Giedd, J. N. (2010). Sex differences in the adolescent brain. Brain and cognition, 72(1), 46-55. DOI

Lürzel, S., Kaiser, S., Krüger, C., \& Sachser, N. (2011). Inhibiting influence of testosterone on stress responsiveness during adolescence. Hormones and Behavior, 60(5), 691-698. DOI

Møller, A. P., \& Garamszegi, L. Z. (2012). Between individual variation in risk-taking behavior and its life history consequences. Behavioral Ecology, 23(4), 843 - 853. $\underline{\text { DOI }}$

Nettle, D. (2010). Dying young and living fast: Variation in life history across English neighborhoods. Behavioral Ecology, 21(2), 387-395. DOI

Nettle, D., Coall, D.A., \& Dickins, T.E. (2011). Early-life conditions and age at first pregnancy in British women. Proceedings of the Royal Society B, 278, 1712-1727. $\underline{\text { DOI }}$

O'Brien, D.T. \& Wilson, D.S. (2011). Community perception: The ability to assess the safety of unfamiliar neighborhoods and respond adaptively. Journal of Personality and Social Psychology, 100(4), 606-620. DOI

Phoenix, C. H., Goy, R. W., Gerall, A. A., \& Young, W. C. (1959). Organizing action of prenatally administered testosterone propionate on the tissues mediating mating behavior in the female guinea pig 1. Endocrinology, 65(3), 369-382. DOI

Rosvall, K.A. (2011). Intrasexual competition in females: Evidence for sexual selection? Behavioral Ecology, 22(6), 1131-1140. DOI

Sanders, S.A., Hill, B.J., Yarber, W.L., Graham, C.A., Crosby, R.A., \& Milhausen, R.R. (2010). Misclassification bias: Diversity in conceptualisations about having 'had sex. Sexual Health, 7(1), 31-34. DOI

Sandseter, E., \& Kennair, L. (2011). Children's risky play from an evolutionary perspective: The anti-phobic effects of thrilling experiences. Evolutionary Psychology, 9(2), 257-284. DOI

Sapienza, P., Zingales, L., \& Maestripieri, D. (2009). Gender differences in financial risk aversion and career choices are affected by testosterone. Proceedings of the National Academy of Sciences, 106(36), 15268-15273. DOI 
Schulz, K. M., Molenda-Figueira, H. A., \& Sisk, C. L. (2009). Back to the future: the organizational-activational hypothesis adapted to puberty and adolescence. Hormones and Behavior, 55(5), 597-604. DOI

Schulz, K. M., \& Sisk, C. L. (2006). Pubertal hormones, the adolescent brain, and the maturation of social behaviors: lessons from the Syrian hamster. Molecular and Cellular Endocrinology, 254-255, 120-126. DOI

Schulz, K. M., Zehr, J. L., Salas-Ramirez, K. Y., \& Sisk, C. L. (2009). Testosterone programs adult social behavior before and during, but not after, adolescence. Endocrinology, 150(8), 3690-3698. DOI

Simpson, J. A., Griskevicius, V., Kuo, S. I., Sung, S., \& Collins, W. A. (2012). Evolution, stress, and sensitive periods: the influence of unpredictability in early versus late childhood on sex and risky behavior. Developmental Psychology, 48(3), 674. DOI

Sisk, C. L., \& Zehr, J. L. (2005). Pubertal hormones organize the adolescent brain and behavior. Frontiers in neuroendocrinology, 26(3), 163-174. DOI

Spear, L. P. (2000). The adolescent brain and age-related behavioral manifestations. Neuroscience \& Biobehavioral Reviews, 24(4), 417-463. DOI

Spear, L. P. (2004). Adolescent brain development and animal models. Annals of the New York Academy of Sciences, 1021(1), 23-26. DOI

Spear, L.P. (2010). The Behavioral Neuroscience of Adolescence. New York, NY: Norton.

Stearns, S. C. (1992). The evolution of life histories (Vol. 249). Oxford: Oxford University Press.

Symons, D. (1979). The Evolution of Human Sexuality. New York, NY: Oxford University Press.

Townsend, J. M. (1999). What Women Want, What Men Want. New York, NY: Oxford University Press.

Van Oers, K., Drent, P. J., De Goede, P., \& Van Noordwijk, A.J.(2004). Realized heritability and repeatability of risk-taking behaviour in relation to avian personalities. Proceedings of the Royal Society of London B: Biological Sciences, 271(1534), 65-73. DOI

Vermeersch, H., T'sjoen, G., Kaufman, J. M., \& Vincke, J. (2008). The role of testosterone in aggressive and non-aggressive risk-taking in adolescent boys. Hormones and Behavior, 53(3), 463-471. DOI

Volk, A.A., \& Atkinson, J.A. (2013). Infant and child death in the human environment of evolutionary adaptation. Evolution and Human Behavior, 34(3), 182-192. DOI

Waller, A. E., Baker, S. P., \& Szocka, A. (1989). Childhood Injury Deaths: National Analysis and Geographic Variations. American Journal of Public Health, 79(3), 310-315. DOI

Wang, X.T., Kruger, D.J., \& Wilke, A. (2009). Life history variables and risk-taking propensity. Evolution and Human Behavior, 30(2), 77-84. DOI 
Wazana, A. (1997). Are there injury-prone children? A critical review of the literature. The Canadian Journal of Psychiatry, 42(6), 602-610. DOI

Wilson, M., \& Daly, M. (1985). Competitiveness, risk-taking, and violence: The young male syndrome. Ethology and Sociobiology, 6(1), 59-73. DOI

Wilson, M., \& Daly M. (1993). Lethal confrontational violence among young men. In N.J. Bell, R.W. Bells (Eds.), Adolescent risk taking (pp. 84-106). Thousand Oaks, CA US: Sage Publications, Inc.

Wingfield, J. C. (2013). The comparative biology of environmental stress: behavioural endocrinology and variation in ability to cope with novel, changing environments. Animal Behaviour, 85(5), 1127-1133. DOI

Wolf, M., Van Doorn, G. S., Leimar, O., \& Weissing, F. J. (2007). Life-history trade-offs favour the evolution of animal personalities. Nature, 447(7144), 581-584. DOI

Zhong, S., Chew, S. H., Set, E., Zhang, J., Xue, H., Sham, P. C., Ebstei R. P. \& Israel, S. (2009). The heritability of attitude toward economic risk. Twin Research and Human Genetics, 12(1), 103-107. DOI

Zuckerman, M. (1994). Behavioral expressions and biosocial bases of sensation seeking. Cambridge university press.

Zuckerman, M., \& Kuhlman, D. M. (2000). Personality and risk-taking: common biosocial factors. Journal of personality, 68(6), 999-1029. DOI 


\section{APPENDIX A}

\section{A Childhood Injury Survey Page}

Injury 1 (the same questions were used for injuries 2-10 as well. Participants rarely reported more than one injury)

The following pages will allow you to enter details about numerous childhood injuries. Please report on this section in regard to the FIRST SUBSTANTIAL CHILDHOOD INJURY that you can recall.

Substantial Injuries are defined as anything that require more than a small bandage.

1. Type of Injury

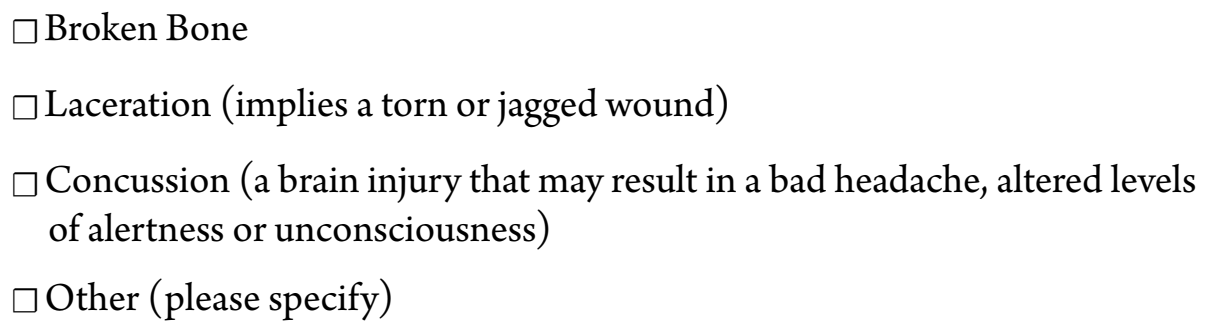

2. Age at time of injury:

3. How was the injury caused? What were you doing at the time of the Injury?

4. How would you rate the severity of the injury?

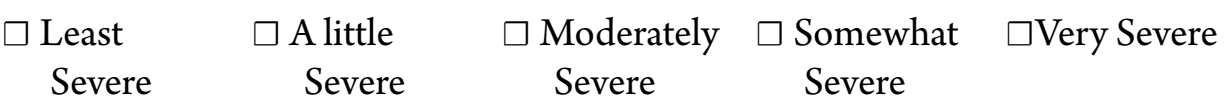

5. Did you have any pre-existing medical conditions during the time of injury?

$\square$ Yes

$\square$ No

6. If yes, please select all that apply:

$\begin{array}{llll}\square \text { Fatigue } & \square \text { Fever } & \square \text { Chills } & \square \text { Sweats } \\ \square \text { Night Sweats } & \square \text { Weight Change } & \square \text { Glaucoma } & \square \text { Cataracts } \\ \begin{array}{l}\square \text { Corrective eye } \\ \text { glasses or lenses }\end{array} & \begin{array}{l}\square \text { Recent visual } \\ \text { change }\end{array} & \square \text { Allergic rhinitis } & \square \text { Frequent sore } \\ \text { throats }\end{array}$




\begin{tabular}{|c|c|c|c|}
\hline $\begin{array}{l}\square \text { Recent hearing } \\
\text { change }\end{array}$ & $\square$ Hearing aid & $\square$ Dentures & $\square$ Sores in mouth \\
\hline$\square$ Frequent cough & $\begin{array}{l}\square \text { Cough up } \\
\text { sputum or phlegm }\end{array}$ & $\square$ Cough up blood & $\begin{array}{l}\square \text { Short of breath at } \\
\text { rest }\end{array}$ \\
\hline $\begin{array}{l}\square \text { Short of breath at } \\
\text { exertion }\end{array}$ & $\square$ Wheezing & $\begin{array}{l}\square \text { Excessive } \\
\text { Snoring }\end{array}$ & $\begin{array}{l}\square \text { Chest tightness, } \\
\text { pressure, or pain }\end{array}$ \\
\hline $\begin{array}{l}\square \text { Swelling in feet or } \\
\text { legs }\end{array}$ & $\begin{array}{l}\square \text { Sleep on more } \\
\text { than one pillow }\end{array}$ & $\begin{array}{l}\square \text { Awaken at night } \\
\text { unable to catch } \\
\text { breath }\end{array}$ & $\begin{array}{l}\square \text { Pounding heart } \\
\text { beats } \\
\text { (palpitations)re } \\
\text { nt vomiting }\end{array}$ \\
\hline$\square$ Light headedness & $\begin{array}{l}\square \text { History of heart } \\
\text { murmur }\end{array}$ & $\begin{array}{l}\square \text { Leg cramps when } \\
\text { walking }\end{array}$ & $\begin{array}{l}\square \text { Frequent } \\
\text { heartburn or } \\
\text { indigestion }\end{array}$ \\
\hline$\square$ Frequent nausea & $\begin{array}{l}\square \text { Frequent or } \\
\text { recurrent } \\
\text { vomiting }\end{array}$ & $\square$ Vomiting blood & $\begin{array}{c}\square \text { Frequent or } \\
\text { recurrent } \\
\text { diarrehea }\end{array}$ \\
\hline$\square$ Constipation & $\square$ Hemorrhoids & $\square$ Blood in stool & $\begin{array}{l}\square \text { Use laxatives } \\
\text { frequently }\end{array}$ \\
\hline$\square$ Painful urination & $\begin{array}{l}\square \text { Get out of bed to } \\
\text { urinate }\end{array}$ & $\square$ Joint pains & $\square$ Joint swelling \\
\hline $\begin{array}{l}\square \text { Frequent } \\
\text { backaches }\end{array}$ & $\begin{array}{c}\square \text { History of } \\
\text { seizures }\end{array}$ & $\begin{array}{c}\square \text { History of } \\
\text { fainting }\end{array}$ & $\begin{array}{c}\square \text { History of } \\
\text { temporary } \\
\text { paralysis }\end{array}$ \\
\hline$\square$ History of stroke & $\begin{array}{l}\square \text { Frequent } \\
\text { headaches }\end{array}$ & $\square$ Depression & $\square$ Anxiety \\
\hline$\square$ Crying spells & $\begin{array}{l}\square \text { Change in } \\
\text { personality }\end{array}$ & $\begin{array}{l}\square \text { Skin lesions or } \\
\text { change in moles }\end{array}$ & $\square$ Skin rash \\
\hline$\square$ Easy bruising & $\begin{array}{c}\square \text { History of } \\
\text { Anemia }\end{array}$ & $\begin{array}{l}\square \text { History of blood } \\
\text { transfusion }\end{array}$ & $\begin{array}{l}\square \text { Swollen lymph } \\
\text { glands }\end{array}$ \\
\hline $\begin{array}{c}\square \text { History of } \\
\text { Thyroid } \\
\text { problems }\end{array}$ & $\begin{array}{l}\square \text { Difficulty } \\
\text { tolerating heat or } \\
\text { cold }\end{array}$ & $\begin{array}{l}\square \text { Recent change in } \\
\text { skin or hair }\end{array}$ & $\square$ History of hives \\
\hline $\begin{array}{l}\square \text { Frequent } \\
\text { pneumonia }\end{array}$ & $\begin{array}{l}\square \text { Removal of } \\
\text { spleen }\end{array}$ & $\begin{array}{l}\square \text { Use of } \\
\text { prednisone or } \\
\text { steroids }\end{array}$ & \\
\hline
\end{tabular}

7. Men Only: 


$\square$ Dribbling of urine $\quad \begin{gathered}\text { Decreased urine } \\ \text { stream and size }\end{gathered}$
$\begin{gathered}\text { Difficulty starting } \\ \text { urination }\end{gathered}$

8. Women Only:

$\begin{array}{lll}\square \text { History of breast } & \square \text { Nipple discharge } & \square \text { Change in periods } \\ \begin{array}{l}\text { lumps or breast tissue } \\ \text { changes }\end{array} & & \\ \square \text { Hot flashes } & \begin{array}{l}\text { Hormonal } \\ \text { medications }\end{array} & \square \text { Change in Period }\end{array}$

9. Did you visit a doctor?

$\square$ Yes

$\square$ No

10. Were you prescribed medication?

$\square$ Yes

$\square$ No

11. Did you visit the hospital?

$\square$ Yes

$\square$ No

12. Did you receive stitches?
$\square$ Yes
$\square$ No

13. If yes, how many stitches did you receive?

14. Did you receive surgery?

$\square$ Yes

$\square$ No 
Johnsen, L. et al.: Youth Injuries Human Ethology Bulletin 32 (2017)3: 85-108 